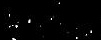


WSRC-TR-92-679

\title{
GROSS ALPHA/BETA DETERMINATION BY LIQUID SCINTILLATION COUNTING (U)
}

\author{
by J. D. Leyba
}

Westinghouse Savannah River Company

WSRC-TR- -92-079

Savannah River Site

Aiken, South Carolina 29808

Other Authors:

\footnotetext{
This paper was prepared in connection with work done under Contract No. DE-AC09-89SR18035 with the U. S. Department of Energy. By acceptance of this paper, the publisher and/or recipient acknowledges the U. S. Government's right to retain a nonexclusive, royalty-free license in and to any copyright covering this paper, along with the right to reproduce and to authorize others to reproduce all or part of the copyrighted paper.
}

\section{MASTER}




\section{DISCLAIMER}

This report was prepared as an account of work sponsored by an agency of the United States Government. Neither the United States Government nor any agency thereof, nor any of their employees, makes any warranty, express or implied, or assumes any legal liability or responsibility for the accuracy, completeness, or usefulness of any information, apparatus, product, or process disclosed, or represents that its use would not infringe privately owned rights. Reference herein to any specific commercial product, process, or service by trade name, trademark, manufacturer, or otherwise does not necessarily constitute or imply its endorsement, recommendation, or favoring by the United States Government or any agency thereof. The views and opinions of authors expressed herein do not necessarily state or reflect those of the United States Government or any agency thereof.

This report has been reproduced directly from the best available copy.

Available to DOE and DOE contractors from the Office of Scientific and Technical Information, P.O. Box 62, Oak Ridge, TN 37831; prices available from (615) 576-8401, FTS 626-8401.

Available to the public from the National Technical Information Service, U.S. Department of Commerce, 5285 Port Royal Rd., Springfield, VA 22161. 


\title{
WESTINGHOUSE SAVANNAH RIVER COMPANY INTER-OFFICE MEMORANDUM
}

\author{
WSRC-TR-92-79 \\ Retention Period: 5 Years \\ KWs: Liquid Scintillation, \\ Gross Alpha/Beta Counting, \\ Low Activity Waste, \\ Screen, \\ Efficiency, \\ Spectrum
}

March 1, 1992

CC: $\quad$ P. F. Cloessner, 773-A

C. W. Jenkins, 773-A

W. R. Jacobsen, 772-3F

R. C. Hochel, 773-A

M. B. Hughes, 772-D

J. C. Griffin, 773-A

J. G. Donnan, 773-3F

R. A. Sigg, 773-A

P. T. Deason, 772-F

F. S. Moore, 773-A

J. D. Heffner, 735-A

R. A. Dewberry, 773-A

R. C. Young, 735-A

A. L. Boni, 773-A

W. G. Winn, 779-9A

K. J. Hofstetter, 779-9A

J. R. Cadieux, 735-7A

W. W. Bowman, 735-A

ADS File

SRL Records (4)

TO: $\quad$ C. E. Coffey, 773-A

FROM: J. D. Leyba, 773-A JPL

\section{GROSS ALPHA/BETA DETERMINATION BY LIQUID SCINTILLATION COUNTING (u)}

\section{Summary}

Liquid scintillation counting (LSC) is used to assay liquid samples for both gross alpha and gross beta (including tritium) activity in order to declare these samples "clean." This method provides several advantages over tracitional gross assay techniques including easy sample preparation, no sample self-absorption, short counting times, acceptable lower limits of detection (LLD's), and convenient sample disposal.

Derivative Classifier:

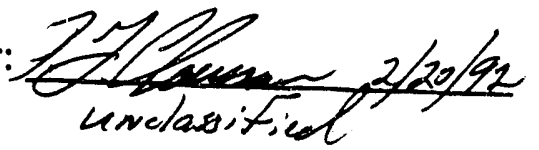




\section{Introduction}

The determination of gross alpna and gross beta activity in aqueous and organic liquid samples is not trivial. Traditionally, these analyses involve the evaporation or electrodeposition of the sample onto a piece of metal and subsequent assay via gas-flow proportional counting. However, when only small amounts of activity are present in a sample, large volumes must be evaporated onto the metal planchet to achieve acceptable LLD's. If a large amount of dissolved solids are present, sample selfabsorption can severely bias the results. Additionally, many organic samples can take up to several hours to evaporate on a planchet.

LSC is an attractive alternative for assaying samples for gross alpha and gross beta activity. This technique requires no sample evaporation, hence sample self absorption is not a problem. Additionally, the detection efficiency for alpha particles is about $90 \%$ versus a maximum of only $50 \%$ for gas-flow proportional counting. For LSC, the beta detection efficiency varies from 50 to $90+\%$ depending upon the beta energy, in comparison to a maximum beta efficiency of only $33 \%$ for gas-flow proportional counting. Finally, LSC has the capability to detect tritium in addition to the other beta emitters present in a sample. Tritium detection is not possible when a sample is evaporated onto a metal plate, since many bound forms of tritium are volatile.

The method employing LSC is intended to screen "clean" liquid samples which have never been in a Radiologically Controlled Area (RCA), samples which have been in RCA's but are not expected to be contaminated, and those samples which contain only small quantities of radionuclides such as the low activity waste (LAW) tanks of Building 773-A. If a sample is analyzed by this method and is found to contain significant quantities of alpha and/or beta-gamma activity, then the sample must be analyzed by other radiochemical techniques to obtain accurate results on the amount of alpha and beta activity present.

\section{Experimental Setup and Results}

Two Packard Liquid Scintillation Analyzers (Models 2250CA and 2550TR) are used to assay samples submitted to ADS. These two analyzers represent the most advanced, versatile liquid scintillation counters currently available from Packard Instrument Company. Each instrument consists of a sample changer, two phototubes, and a PCbased multichannel analyzer. An external $133 \mathrm{Ba}$ source is used to determine the amount of quench present in a sample. Once the quench level is determined, the betaparticle detection efficiency for a given nuclide can be determined. User friendly programs on IBM P/S2 computers provide easy, unattended operation of the instruments. Finally, the sample changer on each instrument can hold over 300 samples; hence, overnight results of multiple samples are easily achievable. 
Sample preparation is accomplished by pipetting a known aliquot of the sample (usually $0.5 \mathrm{~mL}$ ) into $5 \mathrm{~mL}$ of Opti-Fluor or Ultima Gold XR liquid scintillation cocktail. The $6 \mathrm{~mL}$ polyethylene "pony vial" that contains the sample and cocktail is capped and placed into an outer $20 \mathrm{~mL}$ polyethylene liquid scintillation vial to provide double encapsulation. A blank and check standard are also prepared with each set of standards to ensure proper background subtraction and method verification.

Custom designed protocols can be created in order to provide desired counting conditions for the various types of samples and cocktails that are used by ADS. Two custom protocols, one for Opti-Fluor and one for Ultima Gold XR, were created for each instrument. Three regions of interest were set: A) $0-18.6 \mathrm{keV}$, B) $300-800 \mathrm{keV}$, and C) $0-2000 \mathrm{keV}$. Region $A$ is the tritium window, region $B$ is the alpha window, and region $\mathrm{C}$ is the total alpha and beta window. Figure 1.1 shows a typical tritium beta spectrum. Note that the $y$-axis (energy) is a log scale.

A spectrum of a NIST solution containing ${ }^{239} \mathrm{Pu}(91.7$ atom \%), $240 \mathrm{Pu}$ (7.9 atom \%), and ${ }^{241} \mathrm{Pu}(0.3$ atom \%) is displayed in Fig. 1.2. The alpha peak from $239,240 \mathrm{Pu}$, and ${ }^{241} \mathrm{Am}$ (the beta-decay daughter of $241 \mathrm{Pu}$ ) appears in region $\mathrm{B}$ and the low-energy (20.8 keV) beta component from ${ }^{241} \mathrm{Pu}$ is located mostly in region A. Since the endpoint energy of ${ }^{241} \mathrm{Pu}$ is higher than $18.6 \mathrm{keV}$, all of the beta activity from this nuclide will not appear in the tritium window. Note that the energy resolution of the liquid scintillation counter is not good enough to resolve the $5.155 \mathrm{MeV}$ alpha peak of ${ }^{239} \mathrm{Pu}$, the $5.168 \mathrm{MeV}$ alpha peak of $240 \mathrm{Pu}$, and the $5.486 \mathrm{MeV}$ alpha peak of $241 \mathrm{Am}$. The gross alpha disintegration rate of a sample is derived from the count rate in region $\mathrm{B}$, assuming a $90 \%$ detection efficiency. The alpha parti le detection efficiency was determined using NIST-traceable ${ }^{244} \mathrm{Cm}$ and ${ }^{239} \mathrm{Pu}$ solutions. The gross beta disintegration rate is determined by subtracting the alpha count rate in region $\mathrm{B}$ from the total alpha and beta count rate in region $\mathrm{C}$. A conservative average detection efficiency of $50 \%$ is assumed for beta particles. Typical counting times range from 4-10 minutes, however, longer counting times can be used if smaller LLD's are desired.

If the beta activity in a sample is greater than $80 \mathrm{dpm} / \mathrm{mL}$ and/or the alpha activity is greater than $10 \mathrm{dpm} / \mathrm{mL}$, the spectrum must be examined to determine if any of the beta activity is in the alpha region of interest. If any high-energy beta particles appear in the alpha window, inaccurate assay results for both the gross alpha and gross beta count rates will be obtained. For these types of samples, planchets will need to be prepared and assayed on gas-flow proportional counters.

Once the samples have been assayed and activity levels determined, they can easily be disposed of by dumping them down the high level or low level drains. Both Opti-Fluor and Ultima Gold XR are environmentally safe and benign. The only disposal requirement is proper dilution before dumping. 
Figure 1.3 shows a spectrum of a typical aqueous sample submitted to ADS for screening. Note that this sample had no counts in the alpha window. LLD's for a typical $0.5 \mathrm{~mL}$ sample are $<6 \mathrm{dpm} / \mathrm{mL}$ and $<35 \mathrm{dpm} / \mathrm{mL}$ for alpha and beta particles, respectively. These LLD's are well within the "clean" limits currently established by Health Protection (HP) of $<10 \mathrm{dpm} / \mathrm{mL}$ (alpha) and $<80 \mathrm{dpm} / \mathrm{mL}$ (beta). Typical LLD's for evaporated samples are on the order of $700 \mathrm{dpm} / \mathrm{mL}$ for alpha particles and $1400 \mathrm{dpm} / \mathrm{mL}$ for beta particles. These much higher LLD's for evaporated samples stem from the fact that only a small aliquot $(0.075 \mathrm{~mL})$ of a sample is usually evaporated. Small volumes are required in order to keep sample self-absorption and evaporation time to a minimum.

An option will soon be available from Packard Instrument Company which will allow their liquid scintillation analyzer to distinguish alpha particles from beta particles based upon the decay time of the light pulses produced in the cocktail. Once this option is installed, gross alpha and gross beta activity levels can be determined, even in solutions which contain significant quantities of both alpha and beta activities.

\section{Conclusions}

LSC has proven to be an effective method for the screening of samples for both gross alpha and gross beta activity. This method has many advantages including simple sample preparation, no sample self-absorption, short counting times, acceptable LLD's, and convenient sample disposal.

\section{References}

1. "Liquid Scintillation Analysis-Science and Technology," Publication No. 169-3052, Packard Instrument Company, Inc. 1987.

2. Tri-Carb Series Liquid Scintillation Analyzers, Model 2250CA Operation Manual, Publication No. 169-3094, Packard Instrument Company, Inc. 1987.

3. Tri-Carb Series Liquid Scintillation Analyzers, Model 2250TR Operation Manual, Publication No. 169-4044, Packard Instrument Company, Inc. 1990.

4. "Gross Alpha/Beta Determination by Liquid Scintillation Counting," Analytical Development Section Procedure ADS-2424, 1991.

5. "Gross Alpha and Gross Beta," EPA Method 9310, 1986.

6. Table of lsotopes, Seventh Edition, John Wiley and Sons, 1978.

7. National Bureau of Standards Certificate of Analysis, Standard Reference Material 948, Plutonium Isotopic Standard, 1982. 


\section{Figure Captions}

Fig. 1.1 Tritium beta spectrum taken on a Packard 2550TR Liquid Scintillation Analyzer. Region A is the tritium window $(0-18.6 \mathrm{keV})$, region $\mathrm{B}$ is the alpha window (300-800 keV), region $\mathrm{C}$ is the alpha and beta window (0-2000 $\mathrm{keV}$ ).

Fig. 1.2 Spectrum of a solution containing 239,241 Pu taken on a Packard 2550TR Liquid Scintillation Analyzer. Region $A$ is the tritium window $(0-18.6 \mathrm{keV})$, region $\mathrm{B}$ is the alpha window $(300-800 \mathrm{keV})$, region $\mathrm{C}$ is the alpha and beta window $(0-2000 \mathrm{keV})$.

Fig. 1.3 Spectrum of a typical solution submitted to ADS for screening. Spectrum taken on a Packard 2550TR Liquid Scintillation Analyzer. Region A is the tritium window $(0-18.6 \mathrm{keV})$, region $\mathrm{B}$ is the alpha window $(300-800 \mathrm{keV})$, region $\mathrm{C}$ is the alpha and beta window $(0-2000 \mathrm{keV})$. 


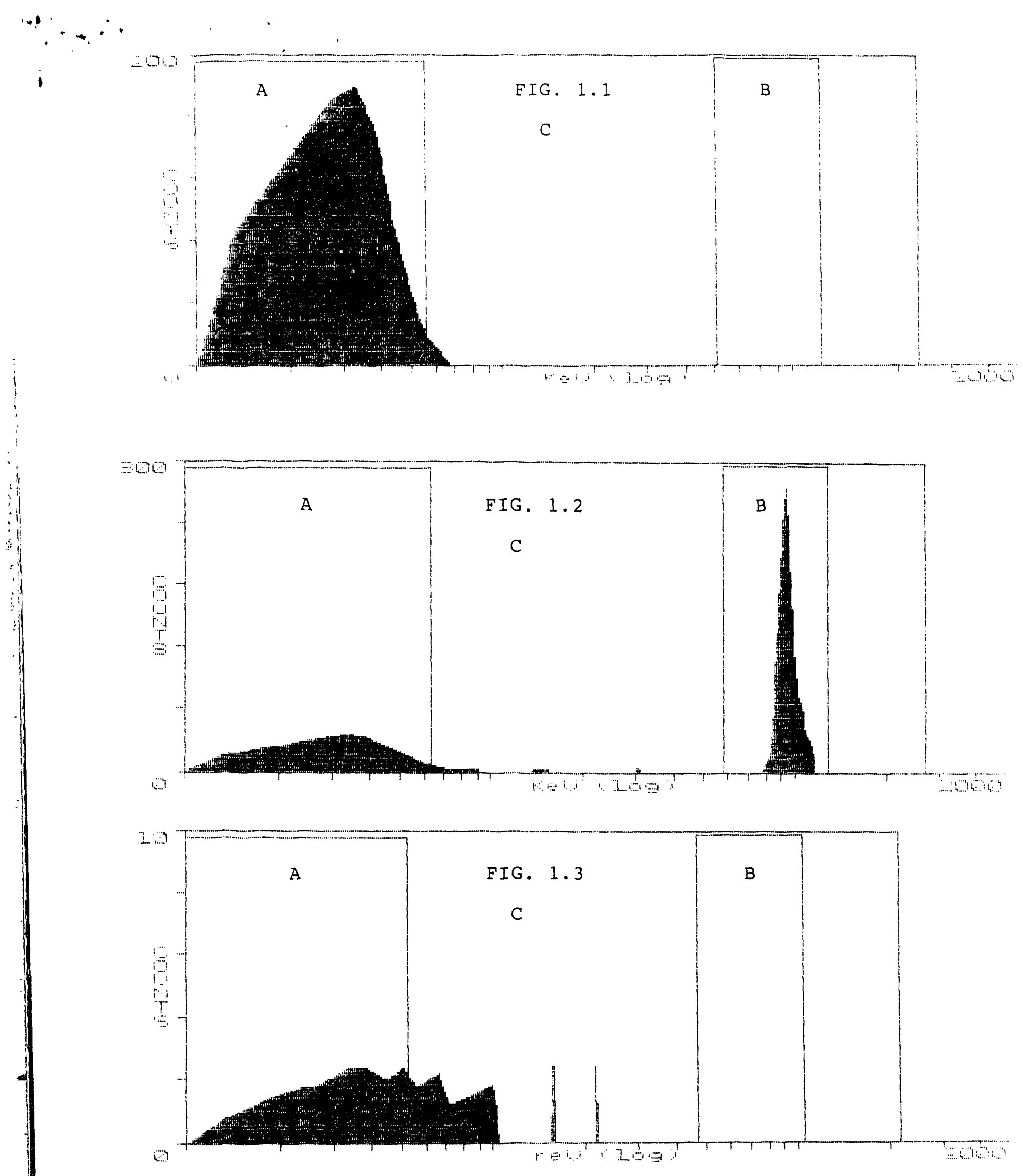



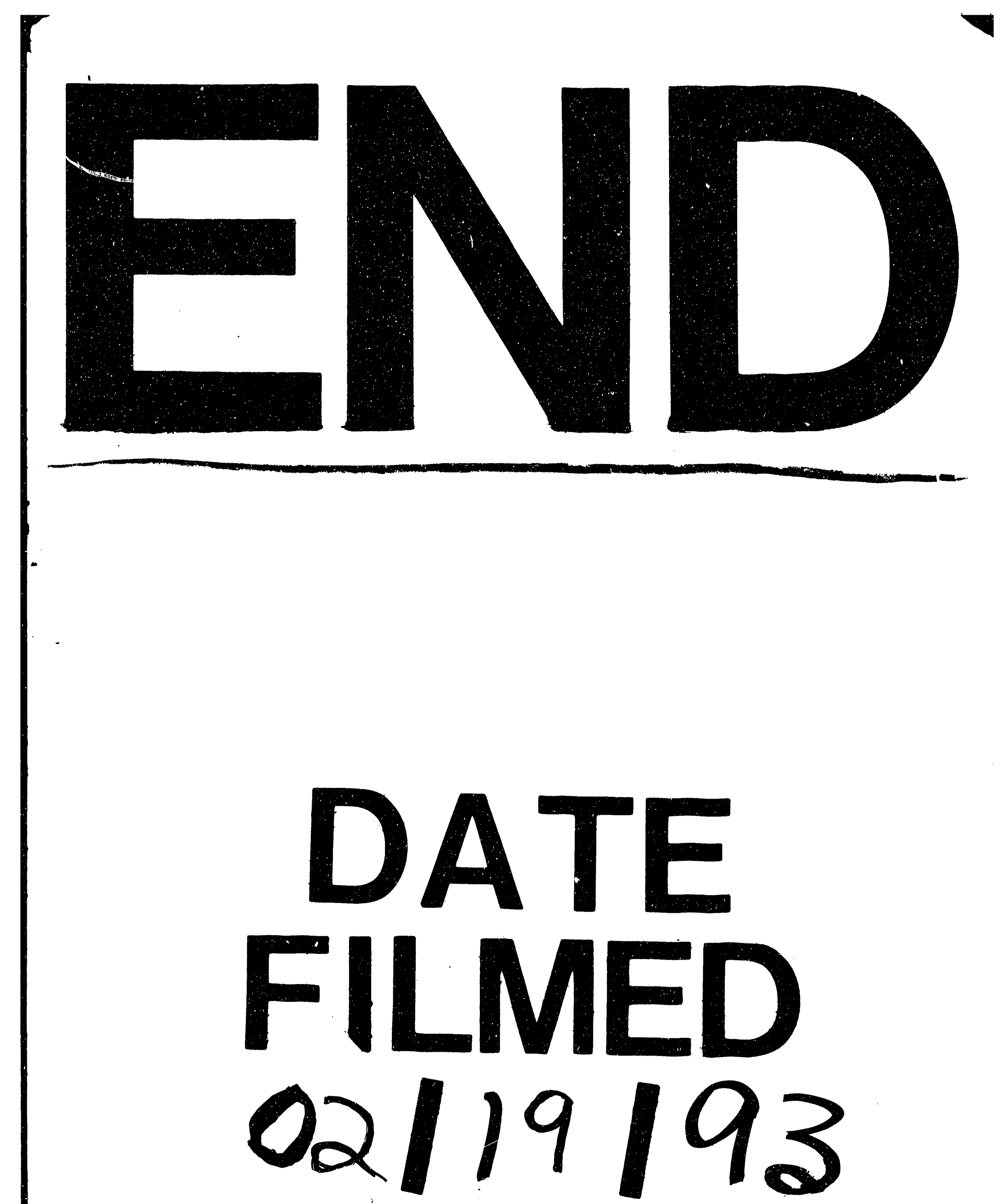
